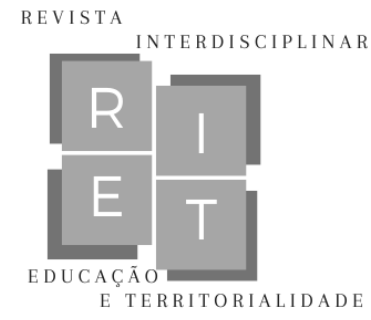

\title{
A educação na pandemia: as relações escola e família permeadas pela tecnologia
}

\author{
Education in the pandemic: school and family relations permeated by \\ technology \\ Educación en la pandemia: la escuela y las relaciones familiares \\ impregnadas de tecnología
}

\author{
Emilia Cipriano Sanches \\ Pontifícia Universidade Católica de São Paulo (PUC-SP) \\ São Paulo, São paulo, Brasil \\ E-mail: emiliacipri@uol.com.br \\ ORCID: https://orcid.org/0000-0002-1679-9721 \\ Sandra Cavaletti Toquetão \\ Pontifícia Universidade Católica de São Paulo (PUC-SP) \\ São Paulo, São paulo, Brasil \\ E-mail: sandracavaletti@gmail.com \\ ORCID: https://orcid.org/0000-0002-6104-9815 \\ Shirlei Nadaluti Monteiro \\ Pontifícia Universidade Católica de São Paulo (PUC-SP) \\ São Paulo, São paulo, Brasil \\ E-mail: shirleinmont@yahoo.com.br \\ ORCID: https://orcid.org/0000-0002-4420-828X
}

Resumo: Este artigo foi elaborado a partir de um documento manifesto apresentando as reflexões de um grupo de pesquisa em Educação e Políticas Públicas da Infância. Dado o trágico impacto imposto pela pandemia causada pela Covid-19 em decorrência da suspensão das atividades pedagógicas relacionadas ao ensino presencial, pretende-se discutir o uso dos meios digitais como possibilidade de realização de momentos de aprendizagem, tanto para os alunos e famílias, bem como para os profissionais da educação. O percurso metodológico utilizado pautou-se no estudo e discussão coletiva de diferentes textos para responder as perguntas emergenciais em tempos de pandemia: como as crianças da primeira infância ficarão no isolamento, em casa? E o papel dos educadores nesse contexto? Como fica a escola com a impossibilidade do acesso pelas crianças e sem tempo previsto para retorno das aulas? O resultado das pesquisas são proposições que possibilitam a reflexão sobre o papel da escola, dos professores, dos gestores e da tecnologia como corresponsáveis pelo atendimento das crianças da primeira infância. Dessa forma, espera-se contribuir com a formação de professores e profissionais da educação que têm como desafio o ensino remoto emergencial com as crianças da primeira infância.

Palavras-chave: Educação Infantil. Pandemia. Formação de Professores. 
Abstract: This article was elaborated from a manifest document presenting a Education and Public politics of childhood's reflections. As the tragic impact due Covid-19's pandemic, as a result of the pedagogical activities suspension related to the classroom teaching, it's intended to discuss the digital ways as possibility of achievement of learning, both for students, family and for education's professionals. The methodological curse was ruled by study and collective discussion about different texts to answer the emergencial questions in pandemics time: how are the first childhood kids going to stay, in isolation, at home?

And what about the education's professionals role in this context? What about the school with the impossibility of kids' access and without forecast classes back? The resources results are propositions that allow the reflection about the school hole, the teachers, managers, and technology as co-responsible for the first childhood kinds attendance. Thus, it's expected to contribute with the teachers and education professionals formation that have as a challenge the remote emergencial study with the first childhood kids.

Keywords: pandemic. teacher training. child education.

Resumen: Este artículo fue elaborado a partir de un documento manifiesto que presenta las reflexiones de un grupo de investigación en Educación y Políticas Públicas para la Infancia. Dado el trágico impacto que ha impuesto la pandemia provocada por el Covid-19 como consecuencia de la suspensión de las actividades pedagógicas relacionadas con la docencia presencial, se pretende discutir el uso de los medios digitales como posibilidad de momentos de aprendizaje, tanto para estudiantes y familias, así como para profesionales de la educación. El camino metodológico utilizado se basó en el estudio y discusión colectiva de diferentes textos para responder preguntas de emergencia en tiempos de pandemia: ¿cómo estarán los niños de la primera infancia en aislamiento en el hogar? ¿Y el papel de los educadores en este contexto? ¿Cómo está la escuela con la imposibilidad de acceso de los niños y sin tiempo para regresar de clases? Los resultados de la investigación son propuestas que permiten reflexionar sobre el papel de la escuela, los docentes, los gestores y la tecnología como corresponsables del cuidado de la primera infancia. De esta forma, se espera contribuir a la formación de docentes y profesionales de la educación que tienen como reto la enseñanza remota de emergencia con niños de la primera infancia.

Palabras Clave: Educación Infantil. Pandemia. Formación de profesores.

Data de recebimento: 03/04/2021

Data de aprovação: 10/06/2021

DOI: $10.30612 /$ riet.v\%vi\%i.14496

\section{Introdução}

Com o surgimento de um novo tipo de coronavírus, o SARS-CoV-2, causador da doença covid-19, o mundo inteiro parou. O isolamento social foi a medida sanitária encontrada pelas autoridades para tentar conter a disseminação da doença. A Organização Mundial da Saúde (OMS) declarou estado de pandemia em março de 2020 e, de acordo com o Fundo das Nações Unidas para a infância (Unicef), criada pela Organização das Nações Unidas (ONU), 154 milhões de crianças ficaram sem aulas presenciais na América Latina e Caribe somente em 2020. 


\section{A educação na pandemia: as relações escola e família permeadas pela tecnologia}

Em nosso país, algumas ações foram tomadas pelo Ministério da Saúde para conter a pandemia, tendo os Estados e os Municípios autonomia, garantida pelo Supremo Tribunal Federal, para a organização e a implementação das ações de combate à covid-19. Guiados pelos órgãos locais de saúde, os governadores e os prefeitos interromperam as aulas presenciais e, para substituí-las, medidas foram tomadas, entre elas, o envio de material didático para as casas das crianças e o incentivo às aulas remotas, utilizando diversos canais midiáticos para a sua realização, que se diferenciaram conforme as regras estabelecidas em cada rede de ensino e em cada Unidade Escolar. Os profissionais da educação tiveram que repensar suas práticas e administrar novas formas de interações a fim de acolher suas crianças e respectivas famílias. Desta forma, constituíram numa velocidade nunca antes observada, com seus próprios recursos, novos referenciais para seguir em suas práticas pedagógicas.

De acordo com o Marco Legal da Primeira Infância, lei de 2016 que garante os direitos relacionados a essa etapa da vida, a primeira infância é entendida como o período da vida que vai da gestação até os seis anos de idade. Entende-se que as infâncias são diversas e as características familiares são repletas de especificidades. Pensando no papel da escola da primeira infância e de seus educadores, a impossibilidade do acesso pelas crianças e a imprevisibilidade do retorno às aulas, surgiram inúmeras reflexões sobre esses acontecimentos. Como as crianças da primeira infância, atendidas na Educação Infantil, provenientes de diferentes famílias, ficariam no isolamento em casa e como a escola da primeira infância poderia atuar nesse período de distanciamento social?

Tentando responder a essa questão, nossos estudos e pesquisas, atrelados à nossa prática pedagógica, realizada nas escolas das infâncias, esboçam nossa posição em relação ao momento vivido. Alguns pressupostos destacados se apoiam em bases sólidas de argumentação, pois foram elaboradas num coletivo de vozes, ideias, de práticas, de estudos e pesquisas baseadas em teóricos da infância, em estudos sociológicos, históricos, filosóficos, que colocam a criança e suas infâncias em primeiro plano.

\section{Desenvolvimento}

A educação é, também onde decidimos se amamos nossas crianças o bastante para não expulsá-las do nosso mundo e abandoná-las a seus próprios recursos, e tampouco arrancar de suas mãos a oportunidade de empreender alguma coisa nova e imprevista para

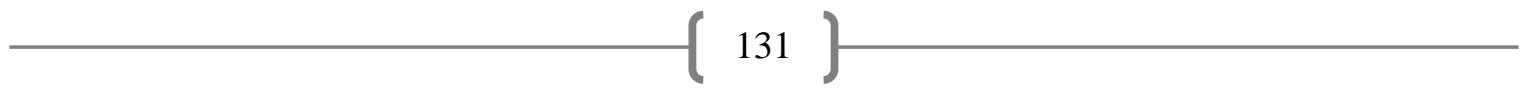

RIET- ISSN 2676-0355, Dourados, v. 2, n. 2, p. 129 a 147, jan./jun., 2021 


\section{A educação na pandemia: as relações escola e família permeadas pela tecnologia}

nós, preparando-as em vez disso com antecedência para a tarefa de renovar um mundo comum. (ARENDT, 2003, p. 247).

Este artigo surge a partir de um documento elaborado em um momento de reflexão de um grupo de pesquisa em Educação e Políticas Públicas da Infância, composto por pesquisadoras, entre mestres, mestrandas, doutoras e doutorandas, atrelado a um curso de pós-graduação stricto sensu, que deu origem a uma publicação. Sua constituição resulta de um momento de perplexidade frente à pandemia e seus desdobramentos sociais, econômicos e educacionais. Uma escolha consciente de não se calar diante das incertezas, inseguranças e transformações desse contexto.

Qual é o nosso legado, como pesquisadoras da infância nesse momento de isolamento social? É uma reflexão sobre o momento vivido na educação e na sociedade brasileira, que possa estar ao alcance de todos os profissionais da educação que se encontram nos mais distantes e diversos lugares, espalhados por todo o nosso país. Esse diálogo, mesmo à distância, somente pode ocorrer com o uso das tecnologias, nosso objeto de estudo neste artigo.

Com o objetivo de contribuir para a discussão de ações e proposições sobre a educação e suas possibilidades de efetivação, espera-se colaborar com a formação de professores e profissionais da educação que têm como desafio, o ensino remoto emergencial com as crianças da primeira infância. Dado o trágico impacto imposto pela pandemia causada pela Covid-19, em decorrência da suspensão das atividades pedagógicas relacionadas ao ensino presencial, pretende-se discutir o uso dos meios digitais como possibilidade de realização de momentos de aprendizagem, tanto para os alunos e famílias, bem como para os profissionais da educação.

Silenciar-se ou posicionar-se como pesquisadoras que estudam as infâncias e a constituição de políticas públicas para garantia de direitos é paradoxal, pois ao mesmo tempo em que vivenciamos a situação e nos sentimos impotentes e sem respostas, vislumbramos também a oportunidade de aprender com este contexto real, preciso, complexo.

Para tanto, no cenário que nos foi imposto, surgiu a necessidade de enfatizar, com coragem e esperança, a defesa daquilo que nos une, que são as crianças, com sua ludicidade e sua potência, tão desconhecidas e não visualizadas, e muitas vezes negadas em seus direitos humanos essenciais. Enfrentar os dilemas se faz necessário, na perspectiva de explicitar nossos princípios, de responsabilidade e solidariedade com a educação. Do ponto de vista 


\section{A educação na pandemia: as relações escola e família permeadas pela tecnologia}

antropológico, algo que exige um compromisso ético com os seres, rompendo o despropósito, o reducionismo e o aniquilamento, com a defesa pelos saberes humanizados contemplados no corpo e mente, no ético e no estético, no acadêmico, sociopolítico, ecológico.

Diante desse triste cenário, nosso caminho metodológico atravessou o estudo e discussão coletiva de diferentes autores para tentar responder as perguntas emergenciais. A partir dos estudos de Arroyo e Silva (2012) realizou-se importante reflexão sobre o quanto é possível a superação dos contextos de opressão, enquanto seres capazes de transgredirem e produzirem cultura mesmo em meio às desigualdades sociais.

Tal como o sociólogo Boaventura de Sousa Santos (2020) destaca em sua recente obra "A cruel Pedagogia do Virus", a pandemia tornou-se mais visíveis as diferenças sociais, a injustiça, a discriminação, a exclusão social e o sofrimento imenso que muitos estão passando. Por isso, tornou-se fundamental a realização de discussões em torno de como possibilitar que todas as crianças tenham assegurado o direito de serem ouvidas e acolhidas em suas necessidades, incluindo as crianças cujas infâncias encontram-se ainda mais precarizadas, como afirma Arroyo e Silva (2012). Na continuidade, inspirou-se em Paulo Freire para fortalecer os coletivos e o diálogo em torno de estratégias que consolidam os princípios em defesa dos direitos contrários a essa lógica perversa.

O mito da neutralidade da educação, que leva à negação da natureza política do processo educativo e a tomá-lo como um que fazer puro, em que nos engajamos a serviço da humanidade entendida como uma abstração, é o ponto de partida para compreendermos as diferenças fundamentais entre uma prática ingênua, uma prática 'astuta' e outra crítica. Do ponto de vista critico, é tão impossível negar a natureza política do processo educativo quanto negar o caráter educativo do ato político. (FREIRE, 1989, p. 23).

O presente artigo lida de forma crítica com a realidade, abrindo mão da pseudoneutralidade, e assim, participa da transformação desse momento de isolamento social, oferecendo contribuições dos estudos sobre infância e exercendo o papel de pesquisadoras e de profissionais da educação básica, que lutam pelos direitos das crianças. Dessa maneira, espera-se que este trabalho, faça parte dos estudos dos professores, nos momentos de formação nas escolas, para que a discussão teórica possa, cada vez mais, se unir ao fazer pedagógico realizado no chão da sala de aula, pois, "aquilo que ensinamos é aquilo que já vivemos, a experiência que construímos. Qual é o maior patrimônio de

RIET- ISSN 2676-0355, Dourados, v. 2, n. 2, p. 129 a 147, jan./jun., 2021 


\section{A educação na pandemia: as relações escola e família permeadas pela tecnologia}

educador? A própria jornada, a história construída ao longo de seu caminho”. (SANCHES, 2019, p. 13).

Para além da crise sanitária, todos devem atuar na construção de ações que minimizem os seus devastadores efeitos, as reflexões podem não dar respostas imediatas, mas gestam em cada autora, o compromisso da ação-reflexão e a busca de alternativas para enfrentar, coletiva e colaborativamente, o desafio da construção de políticas públicas para a infância que possam fazer a diferença no trabalho realizado pelo professor em tempos de pandemia.

A ação formativa proposta tem como princípio uma educação crítica e humanizadora que acontece no contato, na interação, na brincadeira, no afeto e no acolhimento entre pessoas. No momento em que se vive, com o isolamento social, tudo isso fica muito mais difícil. Essa dificuldade se amplia em tempos de negacionismo: da ciência, da universidade, da pesquisa, da educação e principalmente da educação da infância, com políticas públicas que não valorizam o profissional da Educação Infantil. Essa realidade, que bem antes da pandemia, já existia, apresentava grande dificuldade de estabelecer uma rede de proteção, como por exemplo, a falta de vagas para o acesso de bebês e crianças nas escolas de educação infantil e ausência de boas estruturas para um ambiente acolhedor e de qualidade aos pequenos.

A preocupação também se volta para os educadores da infância, que não são valorizados em seus fazeres, e que, no momento de pandemia tiveram seus projetos e planos de trabalho interrompidos. Frustraram-se com seus planejamentos, pois têm consciência das suas dificuldades, apontando os conflitos e tensões do retorno às aulas presenciais, uma vez que os protocolos sanitários quase que inviabilizam as socializações e as sanitizações constantes dos materiais, para que haja o mínimo de segurança para todos os envolvidos, é muito difícil de se realizar. Todas as implicações para organizar um ambiente seguro e acolhedor às crianças, se agravam com a situação de superlotação e falta de professores, problemas já vividos anteriormente ao isolamento social.

\section{Resultados e Discussão}

Escola, educação e tecnologia: uma tríade possível

"Divinizar ou diabolizar a tecnologia ou a ciência é uma forma altamente negativa e perigosa de pensar errado". (FREIRE, 1996, p.37).

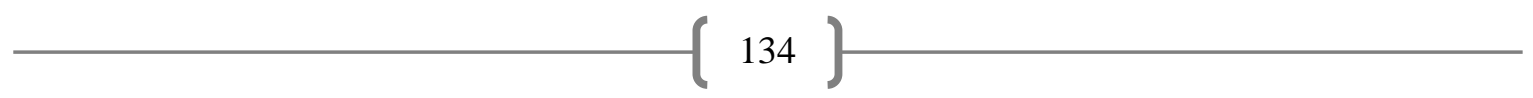

RIET- ISSN 2676-0355, Dourados, v. 2, n. 2, p. 129 a 147, jan./jun., 2021 


\section{A educação na pandemia: as relações escola e família permeadas pela tecnologia}

Os eixos de interação e brincadeira são os pilares que devem permear toda a infância e se manifestam no cotidiano das práticas de diferentes maneiras, estabelecidas entre os sujeitos da ação educativa. Conscientes do papel como educadores e do valor social da educação, e com o firme propósito de contribuir com os estudos sobre infância, apresentase como princípio norteador do trabalho o respeito às crianças e suas múltiplas infâncias. Entende-se que este período da vida, que vai do nascimento aos 12 anos de idade, apresenta especificidades, "conforme a cultura ou a época em que está inserida. Por esse motivo, compreender as especificidades e necessidades da condição de ser criança, só é possível numa perspectiva histórica" (MONTEIRO, 2019, p. 278). O momento vivido é único, as necessidades das crianças precisam estar em primeiro lugar.

Nesse sentido, O currículo Integrador da Infância Paulistana (2015, p. 11), reconhece "a criança como sujeitos de direitos, autônomos, portadores e construtores de história e culturas, em sua experiência com o meio e com os outros, na sua identidade (sua inteligência e sua personalidade)". Esse é o fím único de nossos estudos e pesquisas: tornar a criança o centro da educação da infância.

Sobre a escola e essas relações, o Currículo da Cidade: Educação Infantil aponta que:

a escola é um lugar privilegiado tanto para a ampliação e diversificação de repertórios, saberes e conhecimentos de diferentes ordens como para estabelecer o encontro e a convivência entre bebês, crianças e adultos, a fim de construir outras formas de sensibilidade e sociabilidade que constituam subjetividades comprometidas com a ludicidade, a educação inclusiva, a democracia, a sustentabilidade do planeta, o rompimento de relações de dominação etária, socioeconômica, étnico-racial, de gênero, regional, linguística, religiosa. (SÃO PAULO, 2019, p. 21).

Sem políticas públicas efetivas e eficientes e sem uma formação docente em que se aprenda a olhar para os saberes das crianças e que oportunize, na escola e fora dela, momentos para que produzam cultura, de nada adianta as leis que lhes garantam o acesso às instituições educacionais, se essas leis não saem do papel.

Para possibilitar que o educador da infância compreenda a necessidade de escuta atenta às crianças, é preciso investimento na formação do professor. $\mathrm{O}$ desenvolvimento profissional docente passa pela construção de reconhecer as potencialidades das crianças e das infâncias, pela percepção de suas necessidades, tornando-se importante que educadores escutem, valorizem e incentivem as crianças. Longe do adultocentrismo que ainda se encontra presente nas práticas pedagógicas, certamente, surgirão escolas que permitam

RIET- ISSN 2676-0355, Dourados, v. 2, n. 2, p. 129 a 147, jan./jun., 2021 


\section{A educação na pandemia: as relações escola e família permeadas pela tecnologia}

vivências realmente significativas para bebês e crianças, compreendendo a condição social e o protagonismo deles na produção das culturas infantis, por meio do exercício cotidiano de refinar os olhares diante do imprevisto, das criações, das engenhosidades e das formas como bebês e crianças transgridem as regras impostas pelos/as adultos/as nos espaços públicos da Educação Infantil (SÃO PAULO, 2015, p.10).

As políticas públicas no Brasil precisam avançar, é preciso garantir a todas as crianças um atendimento igualitário e equânime, além de garantir que todos os profissionais da Educação possam ter um desenvolvimento que atenda às necessidades individuais e coletivas das crianças e as especificidades da infância, para além do aprendizado, uma série de outros desdobramentos podem ser apontados, como o crescimento da violência doméstica, da desnutrição e da evasão escolar. Os tempos de crise, com a pandemia, podem tornar-se tempos de redescoberta para reaprender a viver juntos e criar rede de proteção às crianças, realizando ações que aproximem os territórios e que permitam viver com as crianças interações verdadeiras e significativas.

Arroyo (2019) em entrevista publicada na plataforma Educação \& Participação, argumenta que a dicotomia histórica entre humanização de quem pertence aos setores mais favorecidos da sociedade e a desumanização dos mais pobres, é essencial para compreender o papel hoje da escola como espaço de garantia de vida. Estamos em um momento em que a escola tem que pensar radicalmente sobre qual infância e qual adolescência estão chegando até ela.

Pensando nisso, é de extrema importância a formação continuada do professor voltada à formação integral da criança na perspectiva do pleno desenvolvimento e integração. A participação direta das crianças na posição de sujeitos e atores sociais, ativos e criativos, que constroem sentidos e dão significados para coisas, objetos e lugares, se apropriam do conhecimento, cultivam a imaginação e estimulam seus sonhos se tornando crianças pertencentes à cultura em que estão inseridas.

A orientação "\#FiqueEmCasa" veiculada nos principais meios de comunicação, contrasta com as necessidades das infâncias, cujas famílias não conseguem garantir o atendimento de suas necessidades básicas. Sem escola e com pouco espaço físico, as ruas são as únicas alternativas para passar o tempo. Embora as escolas públicas tenham possibilitado meios remotos de acesso à escola, poucas são as crianças que conseguem usufruir dessa tecnologia. 


\section{A educação na pandemia: as relações escola e família permeadas pela tecnologia}

Por outro lado, crianças cujas famílias têm recursos para garantir que as atividades escolares não sejam completamente interrompidas estão imersas num cotidiano marcado pelo excesso de tarefas a cumprir. A obrigatoriedade de acesso às plataformas online e a pouca autonomia para realizarem propostas sem a supervisão dos adultos tem impactado significativamente as suas rotinas e relações afetivas. Pais e responsáveis dividem a atenção entre afazeres domésticos, demandas profissionais e/ou ameaças de desemprego e cuidados com as crianças.

Com a pandemia, temos testemunhado a explicitação de uma desigualdade que acompanha crianças e educadores há muito tempo, modificando profundamente nossa forma de viver em sociedade e evidenciando o desrespeito aos direitos de nossas crianças.

O papel de educadoras e educadores da infância necessita estar comprometido com as crianças, com as suas capacidades e com a maneira como as enxergamos. Na perspectiva de Malaguzzi (2016), a criança precisa ser vista como sujeito da sua própria aprendizagem, ativa, competente e capaz. Nessa perspectiva, será que o momento vivido com a pandemia, materializado em tarefas enviadas às crianças e famílias via sistema on-line, será capaz de proporcionar um ambiente para produzir cultura, promover o desenvolvimento e a aprendizagem esperados pela escola?

Embasados no trabalho de Lajonquière em "Infâncias e Ilusão (psico)pedagógica" (1999), questiona-se acerca da crença de que as experiências de aprendizagens válidas sejam, tão somente, aquelas chanceladas pela instituição escolar, deixando de qualificar as aprendizagens de natureza diferente, ou seja, aquelas resultantes dos tempos vividos em outros espaços.

Assim, como posto por Emília Cipriano $(2020)^{1}$, o tempo vivido pelas crianças junto às suas famílias neste período de pandemia, não é tempo perdido, mas vivido. Considera-se essencial pensar sobre a diversidade de experiências construídas pelas crianças e suas famílias - "experiências de conflito, de superação, de relações que estão sendo percebidas". Em acordo com a pesquisadora, é imprescindível pensar acerca da construção de um planejamento conjunto a partir do entrelaçar da escola, da criança, das famílias e suas realidades. É importante ressaltar que isso será possível mediante o diálogo e a escuta ativa das diferentes vozes, tendo a avaliação conjunta e seu caráter mediador como fator

\footnotetext{
1 (Informação Verbal/ online) Reflexão realizada pela Professora Emília Cipriano na Aula 1 - "As políticas educacionais no cenário de covid-19", Escola do Parlamento, em 26 de junho de 2020.
} 


\section{A educação na pandemia: as relações escola e família permeadas pela tecnologia}

imprescindível no direcionamento e redirecionamento das propostas pedagógicas realizadas na escola.

É preciso considerar toda a vivência da criança em seus contextos familiares. Neles as crianças poderão aprender a cozinhar com seus pais, a arrumar a cama com o irmão mais velho, a regar as plantas com os avós ou a cuidar do irmão mais novo. Serão vivências para além das chanceladas pela instituição escolar, e que farão com que a crianças sejam as protagonistas de suas aprendizagens.

Compartilhar a comida, acompanhar, durante o isolamento social, uma plantinha florescer, guardar seus brinquedos ou conversar à mesa com seus familiares, com certeza serão momentos significativos para o seu desenvolvimento integral, agregando valores, como a empatia, a solidariedade e a comunhão.

É importante que as propostas de aprendizagem sejam desenvolvidas de modo que, possam explorar, descobrir e interpretar coisas a respeito de si e a respeito do mundo. Nesse processo dialógico, que acontece nas interações que realiza, é que surgem as possibilidades de modificar-se e modificar a realidade, ou seja, construir cultura e aprendizagem.

Dentro de tantas inquietações, surge das reflexões construídas no grupo de pesquisa, alguns pontos de apoio, que aos poucos viram pequenas certezas. São momentos de fortalecer e restabelecer os vínculos, pois são tempos inéditos de descobertas e de estudo destas experiências históricas dentro dos ambientes escolares digitais. Ressalta-se que uma parte importante de todo esse processo, é a preparação para o retorno, com o engajamento na construção de uma escola da infância mais humanizadora.

Para isso, é importante a busca de uma educação com equidade, mais inclusiva e integral dentro dos princípios curriculares da ética, estética e política. Esses princípios trazem resumidamente os valores fundamentais da contemporaneidade: solidariedade, singularidade, coletividade, igualdade e liberdade.

Contudo, dentro desses princípios, é preciso nos ater-se à garantia do acesso à educação digital como um direito de todas as crianças. Mesmo nas escolas com maior acessibilidade digital, a adesão aos encontros virtuais é muito baixa. Sabemos que a tecnologia tem a função de potencializar as ações e sentidos dos seres humanos. Os artefatos tecnológicos ampliam nossa possibilidade de enxergar a sociedade com suas construções positivas, entretanto esses artefatos tecnológicos podem dar visibilidade aos desafios da modernidade, além de atuar atuam como enormes "lupas", para apontar os problemas, 


\section{A educação na pandemia: as relações escola e família permeadas pela tecnologia}

principalmente, quando se refere às políticas públicas para a garantia do direito a boas experiências na internet.

Neste momento pandêmico, destaca-se a precarização da escola pública no seu direito ao acesso às novas culturas digitais. Segundo Candau (2011, p. 23),

as relações culturais não são idílicas, não são relações românticas, elas são construídas na história e, portanto, estão atravessadas por questões de poder, por relações fortemente hierarquizadas, marcadas pelo preconceito e discriminação de determinados grupos.

A naturalização das desigualdades entre o ensino privado e o ensino público fica evidente nesta grande "lupa" chamada tecnologia. O discurso do uso democrático das mídias e da importância de acesso à ciência e tecnologia fica longe para as crianças de escola pública. Com as parcerias dos municípios para a educação remota, essas crianças começam a ser inseridas na lógica das plataformas de grandes empresas do capitalismo de vigilância como a Microsoft ou Google, criando contas de e-mail e ambientação nesses espaços digitais. Por conta dessa inserção precoce de bebês e crianças é necessário um diálogo não só pelos direitos à cultura digital, mas vale destacar que o acesso à rede necessita acontecer de forma segura, com proteção de dados de crianças e bebês.

Os efeitos da interação professor e crianças na modalidade digital exclusiva alargam ainda mais as diferenças sociais e econômicas do nosso país, pois o acesso às tecnologias ainda não é realidade para todos. Contudo, a certeza dos direitos e condições de aprendizagem para todos é o combustível diário dos educadores que lutam e resistem à padronização em territórios desiguais. A caminhada para o educador da infância é difícil neste momento, pois além de expor a brutal desigualdade em que se vive, dentro de uma ideologia mercadológica, demonstra a fragilidade de nossas redes de proteção. Fala-se da construção de um modelo de trabalho criativo, coletivo e colaborativo com o uso de tecnologias. Como seria este caminhar com as crianças? Neste trajeto, cheio de desafios na construção de ambientes equitativos, apresenta-se três grandes proposições para a nossa caminhada dentro de uma cultura digital para a infância.

Em primeiro lugar, a qualidade do tempo está relacionada com a construção de vínculos virtuais entre as telas. Já ficou bem discutido que não existe educação infantil à distância, pois a mesma só se desenvolve com as interações entre os diferentes atores da escola, com foco na indissociabilidade do cuidar e educar. Esses cuidados físicos como higiene e alimentação passam por diferentes momentos que são impossíveis de acontecer em

RIET-ISSN 2676-0355, Dourados, v. 2, n. 2, p. 129 a 147, jan./jun., 2021 


\section{A educação na pandemia: as relações escola e família permeadas pela tecnologia}

ambientes digitais. Partindo deste pressuposto, por meio de educadores atentos, algumas relações entre telas podem ser afetivas e com significados para as crianças, ouvir as famílias e as crianças por uma "escuta sensível" e afeta entre telas, pode fazer parte de uma nova relação que se constituirá no processo de ensino e aprendizado.

Com relação às experiências nas atividades remotas emergenciais, tem-se visto que as telas trazem relações inspiradoras que motivam boas interações afetivas com o objetivo de acolher as crianças e suas famílias, possibilitando-lhes sugestões de atividades que pudessem ser feitas em casa. Dentro dessa relação pode-se desenvolver o pensamento criativo e investigativo tão importante para a cognição. Todas estas palavras andam de mãos dadas quando programamos qualquer interação entre estas duas instituições essenciais que cuidam das crianças: a família e a escola. Da mesma forma que é importante esse acesso à cultura digital, algumas preocupações surgem quando pensamos neste diálogo com as famílias pelas telas, como por exemplo, não artificializar o brincar, não forçar uma interação sem significado para a criança.

As brincadeiras necessitam de contexto e significado. Outro destaque importante é referente à qualidade do tempo, pois é preciso ficarmos atentos ao tempo que a criança se dedica nesta interação com a tecnologia digital, respeitando a quantidade indicada por especialistas para cada idade da criança.

Diante disso, algumas dicas podem ser observadas como boas sugestões de interação entre as telas. Uma delas é resgatar a história da escola ou da família para manter os fios afetivos por meio desta comunicação digital. Outra possibilidade é ampliar o repertório das famílias e dar visibilidade ao cotidiano da casa, como quando a criança ajuda no preparo de uma refeição, quando a família conta uma história ou na organização do ambiente. São atividades que valorizam a simplicidade das relações, os ambientes alegres pela presença das crianças, os projetos de brincadeiras, músicas e boas histórias que circulam e fortalecem a construção de diálogos dentro de um ambiente brincante e significativo.

Outro fato a destacar é que vivemos uma hiperdigitalização que precisa ser reconhecida e cuidada em seus excessos. As redes sociais atendem à lógica de mercado e oferecem produtos gratuitos para exploração econômica de dados pessoais, influenciando a sua permanência e consumo nos ambientes digitais. Dessa forma, é preciso atenção quando o assunto é qualidade no tempo de tela. 


\section{A educação na pandemia: as relações escola e família permeadas pela tecnologia}

Ao pensar em aplicativos e analisar a qualidade das interações, é preciso observar a faixa etária e o tipo de conteúdo indicados, a segurança dos dados da criança na plataforma, quem é a companhia presente e quais são as boas perguntas para mediar a relação entre adultos, crianças e telas. É necessário refletir se a interação com o aplicativo é passiva e padronizada, no qual a criança é silenciada para somente assistir e neutralizar suas ações. Ou é reflexiva e reativa, em que estimula o diálogo, oferece possibilidades de cantar e brincar e permite que a criança emita opiniões. Aprofundando mais ainda essa interação com as telas, é preciso questionar se o aplicativo apresenta situação com sentido e possibilita a representativa das etnias, da cultura e da história do território.

Só assim, levando essas considerações para as famílias e os educadores, criamos um canal de comunicação sensível com e para as crianças, para que, de acordo com Candau (2011 p. 13), "possa oferecer espaços e tempos de ensino-aprendizagem significativos e desafiantes para os contextos sociopolíticos e culturais atuais".

Dessa maneira, é preciso compreender que as tecnologias fazem parte da cultura digital, os diálogos reais e afetivos podem acontecer com as telas, e para além das telas. As contradições no conviver são muitas, dessas diferentes infâncias, mas todas, neste momento do brincar entre telas de celular, televisão ou tablet precisam ter como eixo o acolhimento e o cuidado das famílias e das crianças. Segundo Candau (2011, p. 13), "não é possível conceber experiência pedagógica desculturizada, isto é, desvinculada totalmente das questões culturais da sociedade".

As abordagens nas orientações priorizam as vozes e autorias das famílias. As famílias podem ser reconhecidas em seus saberes, fazeres e em sua história. Durante o período de isolamento social, é ainda mais importante respeitar a organização dos lares, os sofrimentos causados por perda como o emprego ou de pessoas queridas. É um grande desafio entrar nas casas das crianças pelas telas e ampliar a participação das famílias na rede de comunicação digital.

A terceira proposição a ser refletida são as políticas públicas intersetoriais. A escola, por si só, não consegue responder aos desafios de educar em tempos de pandemia em busca de uma educação para a inclusão digital. Para Candau (2011, p. 23), enfrentar conflitos provocados pela assimetria de poder numa educação para negociação cultural pode ser capaz de "favorecer a construção de um projeto comum, pelo qual as diferenças sejam dialeticamente incluídas".

RIET- ISSN 2676-0355, Dourados, v. 2, n. 2, p. 129 a 147, jan./jun., 202 


\section{A educação na pandemia: as relações escola e família permeadas pela tecnologia}

Na mesma linha da autora, apontamos a necessidade da construção de novas parcerias, pois a escola e a família não podem ficar sozinhas para pensarem na educação das crianças em tempos tão desafiantes. A responsabilidade pelas experiências digitais das crianças deve ser compartilhada com toda a sociedade. É preciso tecer uma rede colaborativa de proteção entre comunidade, escola, família e implicar-se em políticas que considerem a dimensão educativa além da escola

Cada uma destas instituições tem seu papel em destaque que é proteger os direitos das crianças, pois, nem sempre elas se encontram num ambiente favorável ao seu desenvolvimento. Às vezes são espaços com os mais diversos tipos de violência que não podem ser desconsiderados neste momento de isolamento familiar. Uma das funções desta rede de proteção é construir fontes confiáveis para a famílias e a escola, realizando a curadoria de materiais que trazem a concepção de infância ativa e com proteção à criança.

Mas vai além disso, é preciso ter a sensibilidade desenvolvida na comunidade para investigar se alguma criança vem sofrendo a violação de seus direitos e denunciar para os órgãos que atuam na prevenção e proteção de situações de violência. Ter o conhecimento sobre a infância e como se aciona a rede de proteção do território, é um caminho para superar as desigualdades, fazendo a informação chegar até os órgãos de atuação e criando demanda para essas instituições.

Para isso, precisamos do papel ativo de cidadão em cada um de nós, profissionais da educação, para fazer valer as leis relacionadas aos direitos das crianças, que no Brasil já está bem encaminhada na sua criação. Mas falta ainda que os direitos garantidos pelas legislações cheguem, efetivamente, até as crianças. Nesse sentido, é importante a cidadania crítica, participativa e atuante na construção das políticas públicas, criando meios de acesso digital com informação de qualidade para a população mais carente que tem seus direitos negados e neste momento ainda mais destacados.

A educação da primeira infância, nesse momento atípico, ganha maior visibilidade e fortalece a compreensão das crianças como sujeito em desenvolvimento, com suas singularidades que interferem nas formações identitárias e culturais. Nessa perspectiva, demandam práticas escolares diferenciadas que atendam às necessidades nos diversos modos de inserção social. O momento escancarou a necessidade da adaptação e articulação de ações para ampliar a compreensão pela vida social de forma humanizada e integrada, relacionando os sujeitos entre si, com a natureza, com a história, com a cultura, com as tecnologias e com

RIET- ISSN 2676-0355, Dourados, v. 2, n. 2, p. 129 a 147, jan./jun., 202 


\section{A educação na pandemia: as relações escola e família permeadas pela tecnologia}

o ambiente para melhor afetar, conectar e transformar o aluno em seu percurso contínuo de aprendizagem e desenvolvimento.

Agarradas nessa premissa, a articulação de diferentes saberes, linguagens e conhecimentos, por meio de práticas pedagógicas integradoras e interações afetivas, ressignifica a intencionalidade docente, os momentos de ensino e aprendizagem, a qualificação de tempos, espaços, interações e materialidades. O ensino centrado na criança como sujeito em seu processo de aprendizagem, volta a atenção para experiências concretas e interativas para a mobilização de saberes por meio das telas e para além das telas.

A pandemia terá um impacto mundial duradouro, principalmente em país em desenvolvimento. São desafios das condições econômicas, psicossociais e sanitárias que se agravaram com o distanciamento das classes sociais, da educação e, dessa forma, necessita pensar caminhos para minimizar estes impactos, reivindicando ações pontuais contra a precariedade do acesso que interfere ainda mais no desenvolvimento infantil.

Importa salientar que, a pandemia trouxe um desafio extra para as famílias com o ensino remoto na educação da infância, sobretudo às que vivem em condições de vulnerabilidade, e a escola tem a missão de aproximar e integrar a família para fortalecer o sentimento de pertencimento e parceria frente à corresponsabilização de ações que garantam os direitos da infância.

O cenário ainda é de muitas dúvidas e incertezas, porém o ser humano em potência, que se dedica ao que lhe transcende, predispondo-se ao que transforma, inova e renova como pessoa, em uma corrente em que cada um fortalece os demais para o que é essencial, pois tudo está conectado.

\section{E para finalizar, a história continua...}

"É preciso uma aldeia para se educar uma criança". Provérbio Africano

Partindo desse provérbio africano, acredita-se que nenhuma pessoa aprende e se desenvolve somente a partir dos valores de sua família, mas também com toda a comunidade em que vive e se relaciona, e a escola faz parte deste meio social. Desde o início da pandemia, nas escolas, especialmente as que atendem a primeira infância, ações pedagógicas estão sendo pensadas tendo como foco o acolhimento. Em menor ou maior grau, as escolas visam 


\section{A educação na pandemia: as relações escola e família permeadas pela tecnologia}

dar conta do seu papel formador, levando em consideração suas características específicas, a comunidade que a compõe e as suas realidades.

Cada escola tem a sua concretude e precisa levar em consideração seu contexto para elaborar coletivamente ações durante e após pandemia. Mas cada unidade escolar, sob a orientação e coordenação de seus gestores, tem buscado o contato com as famílias, com os alunos. Os professores têm-se reinventado, buscando formas de ter acesso a esses alunos, para que não se sintam sozinhos nesse momento tão difícil que estamos vivendo.

Por meio de instrumentos tecnológicos, as escolas da primeira infância têm se adaptado, realizando a comunicação com as crianças e as famílias, utilizando as redes sociais como WhatsApp, Facebook, Google Class Room, Microsoft Teams, para orientação em relação à rotina de estudos, às possibilidades de brincar, às questões comportamentais, além de contações de histórias e atividades com músicas, que trazem em seu repertório as competências socioemocionais da BNCC. Para as crianças do Ensino Fundamental, plataformas online têm sido utilizadas para que os professores possam realizar aulas remotas. Nem sempre é possível que todos tenham acesso, mas esse não é um motivo de desânimo para o professor da infância. Ele é capaz, é criativo, perseverante. E, ao mesmo tempo, pode denunciar, por meio das comunicações digitais, a falta de acesso digital e não desanimar frente às adversidades.

Que a tecnologia, aqui referenciada como uma possibilidade de estreitamento entre a família e a escola, seja um direito de todos, não só em tempos de pandemia, mas que possa ser mais um instrumento para a aprendizagem dos alunos, não importando a classe social.

Acreditamos na formação continuada do professor, como oportunidade para reflexão sobre sua prática pedagógica, atuando como pesquisadores em suas escolas e também nas universidades, e a partir desses estudos, discutir novos horizontes para a formação integral de nossas crianças, quando as aulas presenciais retornarem.

Será preciso um novo olhar para a escola pós-pandemia, pois além dos desafios relacionados às aprendizagens cognitivas, encontraremos pessoas com sentimentos fragilizados, com perdas financeiras e de vidas nas famílias, enfim, crianças e adultos necessitando de mais atenção e de cuidados.

O retorno precisa ser muito bem planejado, e não pode ser pensado de forma individualizada pelas instituições. É preciso que haja o envolvimento dos vários segmentos da sociedade, em níveis institucionais e de forma intersetorial, abrangendo as instituições

RIET- ISSN 2676-0355, Dourados, v. 2, n. 2, p. 129 a 147, jan./jun., 202 


\section{A educação na pandemia: as relações escola e família permeadas pela tecnologia}

nas áreas da saúde, assistência social, tribunal de contas e os conselhos de educação, uma vez que esse é um desafio histórico de toda a sociedade, o que nos encaminha ao entendimento de que é necessário recorrer às políticas públicas para esse enfrentamento, tamanha é a seriedade da situação.

Compreende-se que o reencontro e o restabelecimento das relações são fundamentais e inevitáveis, no entanto, precisa ocorrer de forma responsável, com protocolos predeterminados e regras estabelecidas.

Para promover o retorno, os professores e demais profissionais da escola, precisam muito ser ouvidos, ser instruídos, precisam ser cuidados para que eles se expressem, demonstrem seus sentimentos, dores, medos, para que possam, ao se aproximar dos familiares e crianças, inspirar confiança e segurança, uma vez que o docente é o mediador direto da convivência e estabelecimento da relação da criança com o ambiente escolar.

A equipe gestora terá um papel mais que fundamental na organização dos espaços e no cuidado com o acolhimento às famílias e às crianças, já que toda organização escolar passa pelo seu crivo e a execução de protocolos e estruturação do espaço para o retorno será de responsabilidade de todos, porém, estará sob o comando da equipe gestora. É possível que muitas crianças estejam sentindo falta da escola, dos professores e de seus amigos, afinal a escola é o lugar de encontros, de trocas e de aprendizagens, é nela que há a mais pura expressão de ser criança, de ser adolescente.

Resta a pergunta: de que lugar estamos falando sobre a infância e a pandemia? Procuramos neste documento, desvelar concepções e posicionamentos sobre a criança, suas infâncias e seu lugar no mundo, diante desse isolamento social.

Fica um alerta para as autoridades e os órgãos competentes que fortaleçam as políticas públicas para a educação com um olhar cuidadoso para a criança em meio ao caos que assola o mundo. As políticas públicas precisam alcançar as crianças vulnerabilizadas e suas famílias, garantindo segurança, bem-estar e condições mínimas de sobrevivência.

A melhoria das condições de trabalho para os professores e gestores com investimentos em merenda escolar, melhores estruturas físicas, aumentos salariais e materiais pedagógicos também precisam ser garantidos pelos órgãos competentes.

Não silenciem os pedidos de socorro de famílias e crianças! Elas estão clamando por uma política pública que leve em consideração seus direitos, suas necessidades básicas de alimento, saúde, respeito e cuidados. É dever de uma sociedade democrática, nesse 


\section{A educação na pandemia: as relações escola e família permeadas pela tecnologia}

momento, ser a voz que clama por esse socorro, que só pode vir de pessoas ligadas à educação da infância, que acreditam na urgência desse clamor.

Que os líderes de nosso país possam pensar em nossas crianças, com seriedade e comprometimento, que discutam com todos os segmentos sociais, políticos e econômicos a verdadeira e necessária ajuda que as nossas crianças tanto precisam, não só nesse tempo de pandemia, mas no cotidiano de suas existências, muitas vezes invisíveis aos nossos olhos.

Esta reflexão precisa ser a marca de um momento vivido. Ela é histórica, na medida em que permite o diálogo entre as nossas convicções e os leitores, que comungam da mesma certeza, a defesa da educação da infância. Qual é a história que estamos construindo que representa nosso legado? Dentre os limites sócio-históricos que o momento nos impõe, esta é a nossa contribuição para a educação: a possibilidade de denúncia e o anúncio de algumas ações, com a coragem de quem acredita que somos seres inacabados e que nos completamos com o outro, em busca de novas possibilidades. Como afirmou Paulo Freire:

a amorosidade de que falo, o sonho pelo qual briga e para cuja realização me preparo permanentemente, exigem que eu invente em mim, na minha experiência social, outra qualidade: a coragem' de lutar ao lado da coragem de amar. (FREIRE, 1997, p. 37).

A amorosidade, construída nas interações que ocorrem na escola, se entrelaça com a comunicação, por meio da tecnologia para suprir a ausência física. Como professores que realizam as mediações necessária para a aprendizagem, ainda estamos disponíveis para nos surpreendermos e nos encantarmos, por meio da amorosidade freireana e de mãos dadas com nossas crianças!

Deixemos a infância florescer, porque a história continua...

\section{Referências}

ARENDT, Hannah. Entre o passado e o futuro. São Paulo: Perspectiva, 2003.

ARROYO, Miguel Gonzalez; SILVA, Maurício Roberto da (Orgs.). Corpo infância: exercícios tensos de ser criança; por outras pedagogias dos corpos. Petrópolis: Vozes, 2012.

ARROYO, Miguel. Um professor em contato com as crianças é obrigado a se repensar. Revista Aliança Brasileira pela Educação. Disponível em: https://www.cenpec.org.br/tematicas/miguelarroyo-um-professor-em-contato-com-as-criancas-e-obrigado-a-se-repensar Entrevista concedida em 22/04/20219. Acesso em: 02/05/2020.

BRASIL. LEI N 13.257, DE 8 DE MARÇO DE 2016. Marco legal da Primeira Infância. Dispõe sobre as políticas públicas para a primeira infância. Brasília, 2016. 
A educação na pandemia: as relações escola e família permeadas pela tecnologia

CANDAU, Vera Maria. Multiculturalismo: desafios para a prática pedagógica. In: Candau, Vera Maria; Moreira, Antonio Flávio. (Orgs.). Multiculturalismo: diferenças culturais e práticas pedagógicas. Petrópolis, RJ: Vozes, 2011.

FREIRE, Paulo. A importância do ato de ler: em três artigos que se completam. São Paulo: Autores Associados: Cortez, 1989.

, Paulo. Pedagogia da autonomia: saberes necessários à prática educativa. 31 ed. São Paulo: Paz e Terra, 1996. 1997. Paulo. Professora sim, tia não: cartas a quem ousa ensinar. São Paulo: Olha D’Água,

LAJONQUIÈRE, Leandro de. Infância e ilusão (psico)pedagógica: escritos de psicanálise e educação. São Paulo, Vozes, 1999.

MALAGUZZI, Loris. História, ideias e princípios básicos: uma entrevista com Loris Malaguzzi. In: EDWARDS, Carolyn; GANDINI, Lella; FORMAN, George. As cem linguagens da criança: a experiência de Reggio Emilia em transformação. V. 2. Porto Alegre: Penso, 2016.

MONTEIRO, Shirlei Nadaluti. A primeira infância e a escola - concepção de criança, infância e de escola: uma construção histórica. In: SANCHES, Emília Maria Bezerra Cipriano Castro; TOQUETÃO, Sandra Cavaletti; OLIVEIRA, Fernanda Souza de. (Orgs.) Achados de pesquisa na educação da infância. Campinas, S.P.: Pontes Editores, 2019.

ORGANIZAÇÃO MUNDIAL DA SAÚDE. (2020). Disponível em:

https://www.who.int/eportuguese/publications/pt/. Acesso em: 28 abr. 2020.

SANCHES, Emilia Cipriano. Saberes e afetos do ser professor. São Paulo: Cortez. 2019.

SANCHES, Emilia Cipriano; TOQUETÃO, Sandra Cavaletti; MONTEIRO, Shirlei Nadaluti (Orgs.). Uma janela de possibilidades na educação da infância em tempos de pandemia. Manifesto do Grupo de Pesquisa de Políticas Públicas da Infância-Criando PUC-SP,1 ed. , ed. Campinas, SP: Pontes Editores, 2020.

SANTOS, Boaventura de Sousa. A Cruel Pedagogia do Vírus. Coimbra: Edições Almedina, 2020.

SÃO PAULO. Secretaria Municipal de Educação. Coordenadoria Pedagógica. Currículo da cidade: Educação Infantil. São Paulo: SME/COPED, 2019.

SÃO PAULO. Secretaria Municipal de Educação. Diretoria de Orientação Técnica. Currículo integrador da infância paulistana. São Paulo: SME/DOT, 2015. 